\title{
Effect of dietary arginine supplementation on reproductive performance of mice with porcine circovirus type 2 infection
}

\author{
Wenkai Ren · Yulong Yin • Gang Liu • \\ Xinglong Yu $\cdot$ Yinghui Li $\cdot$ Guan Yang • \\ Teijun Li $\cdot$ Guoyao Wu
}

Received: 4 April 2011/Accepted: 11 May 2011/Published online: 27 May 2011

(C) The Author(s) 2011. This article is published with open access at Springerlink.com

\begin{abstract}
The objective of this study was to investigate whether supplemental dietary arginine increases reproductive performance in mice infected with porcine circovirus type2 (PCV2). A total of 50KM female mice were allotted randomly to the arginine group $(0.6 \%$ arginine + gestation diet) and control group $(1.22 \%$ alanine + gestation diet). All the mice began to mate after 14 days of treatment with our prepared feed and challenged with PCV2 at the dose of $100 \mathrm{TCID}_{50}(50 \%$ tissue culture infection dose, $\mathrm{TCID}_{50}$ ) after 7 days of pregnancy. Abortion rate, litter number, litter birth weight, the daily weight gain in the first 7 days and survival rate in the first 2 weeks of the neonates were calculated. The serum progesterone, estrogen, nitric oxide and superoxide dismutase (SOD) activity and total antioxidant capacity (T-AOC) on the 14th
\end{abstract}

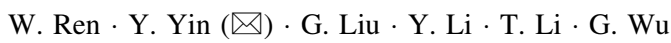

Research Center for Healthy Breeding of Livestock and Poultry,

Hunan Engineering and Research Center of Animal and Poultry

Science and Key Laboratory for Agro-ecological Processes in

Subtropical Region, Institute of Subtropical Agriculture,

The Chinese Academy of Sciences, Hunan 410125, China

e-mail: yinyulong@isa.ac.cn

G. Liu

e-mail: gangle.liu@gmail.com

W. Ren · Y. Li

Graduate School of Chinese Academy of Sciences,

Beijing 100039, China

$\mathrm{X} . \mathrm{Yu}(\bowtie)$

College of Veterinarian, Hunan Agricultural University,

Changsha 410128, Hunan, China

e-mail:xlyu999@yahoo.com.cn

G. Yang

College of Animal Science and Technology, Hunan Agricultural

University, Changsha 410128, Hunan, China day of pregnancy were measured. Arginine supplementation decreased the abortion rate of pregnant mice and mortality of neonates caused by PCV2 infection. Further, litter number, litter birth weight and the daily weight gain of neonates increased in the arginine group compared to the control group. Arginine supplementation increased significantly the serum progesterone $(P<0.01)$ and nitric oxide levels $(P<0.05)$, but had little effect on the serum estrogen level. SOD activity and T-AOC in the arginine group were significantly higher $(P<0.01)$ than the control group. In conclusion, arginine supplementation partially reversed the reproductive failure in mice caused by PCV2 infection.

Keywords Arginine - Porcine circovirus · Progesterone · Nitric oxide
Abbreviations
PCV2 Porcine circovirus type 2
SOD Superoxide dismutase activity
T-AOC Total antioxidant capacity

\section{Introduction}

Porcine circovirus diseases (PCVD) or porcine circovirusassociated diseases (PCVAD) were responsible for significant economic losses to the swine industry worldwide. Presently, porcine circovirus type 2 (PCV2) has been recognized as the essential infectious factor of PCVD or PCVAD (Segales and Allan 2005). PCV2 had also been associated with a range of other disorders of pigs including respiratory as well as reproductive disorders, dermatitis and nephropathy syndrome (PDNS) (Segales and Rosell 2004). PCV2 infections were divided into pre- and post-natal manifestations. In the former, PCV2 infection was linked 
to reproductive failures (West and Bystrom 1999; Ladekjaer-Mikkelsen and Nielsen 2001; O'Connor and Gauvreau 2001; Kim and Jung 2004).The main clinical signs of affected sows included elevated abortion, stillbirths and fetal mummification. Other research also reported that PCV2 could infect porcine embryos and foetuses (Johnson and Joo 2002; Mateusen and Sanchez 2004; Mateusen and Maes 2007) and even spread through intrauterine (Pensaert and Sanchez 2004) and vertical transmission (Park and Kim 2005; Rose and Blanchard 2007).

Arginine, a conditionally essential amino acid, was a substrate for several non-proteins, nitrogen-containing compounds (Kim et al. 2007; Tan et al. 2010 and 2011). Research indicated that arginine participated in the regeneration of adenosine triphosphate, cell proliferation, vasodilatation, neurotransmission, calcium release and ultimately immunity. Arginine metabolism generated several functional compounds, such as creatine, polyamines, agmatine and nitric oxide (NO) (Nieves and Langkamp-Henken 2002; Li and Yin 2007). NO played an important role in physiological events (e.g., ovulation and placental growth) and in pathological conditions (virus and bacteria infection) (Battegay 1995). In addition, arginine stimulated the secretion of anterior hormones and placental lactogen in humans and animals, thereby regulating the conceptus development (Flynn and Meininger 2002). Mateo reported that dietary supplementation with $1.0 \%$ arginine-HCl between days 30 and 114 of gestation increased the number of live-born piglets by two and litter birth weight by $24 \%$ (Mateo and $\mathrm{Wu} 2007$ ).

We hypothesized that dietary arginine supplementation could inverse the reproductive failure caused by PCV2 in mice. Thus, the objective of this study was to determine whether increasing dietary arginine intake in PCV2-infected mice improved reproductive performance.

\section{Materials and methods}

Animal and experimental protocol

A total of 50KM female mice with primiparity were obtained from the Laboratory Animal Center of Central South University, Hunan, China. The mice were housed in a pathogenfree mouse colony (temperature, $20-30^{\circ} \mathrm{C}$; relative humidity, 45-60\%; lighting cycle, $12 \mathrm{~h} /$ day) and had free access to food and drinking water. The mice were randomly assigned to the arginine group $(0.6 \%$ arginine + gestation diet, $n=25)$ or the control group $(1.22 \%$ alanine + gestation diet as isonitrogenous, $n=25$ ). The mice had intake of their particular feed after 3 days of accommodation. Further, the amino acid content in the gestation diet was measured using Automatic Amino Acid Analyzer (AAAA). Mice started to mate on the 14th day after feeding on arginine. The observable pessus was regarded as a prerequisite for judging the copulation. Finally, 19 and 18 mice mated successfully in arginine group and control group, respectively. All the mice were infected with PCV2 $\left(100\right.$ TCID $\left._{50}\right)$ on the 7th day after pregnancy, and six mice from each group were killed to collect serum on the 14th day after pregnancy. All animal experiments were performed according to the guidelines of the Laboratory Animal Ethical Commission of the Chinese Academy of Sciences (Fan et al. 2005).

Data collection

Abortion rate, litter number, litter birth weight and the daily weight gain in mice in the first 7 days and survival rate in the first 2 weeks of the neonates were calculated. The progesterone and estrogen in the serum were measured using enzyme-linked immunosorbent assay (ELISA) (CUSABIO BIOTECH CO.,LTD, China).NO level in the serum was detected by the method of nitric acid reductase (NJJCBIO.China). Total SOD activity and T-AOC in the serum were determined using spectrophotometric kits at $550 \mathrm{~nm}$ (Nanjing Jiancheng Biotechnology Institute, China) according to the manufacture's instructions.

Data from the experiment was processed by Excel 2003 and analyzed by Statistic software SPSS16.0. The result was expressed with mean \pm standard error of the mean (SEM).

\section{Results}

Amino acid content in the gestation diet is shown in Table 1. In the arginine group, two mice (total 13 mice) had abortion; however, three mice in the control group (total 12 mice) aborted (Fig. 1). Litter number increased in the arginine supplementation group compared to the control group (Table 2). Moreover, dietary arginine supplementation increased birth weight, but no statistical significance was found $(P=0.304)$ (Table 2).

Previous study found that the neonates could not growth normally and the survival rate was very low (data not shown) because of PCV2 infection. To judge the advantages of arginine supplementation of the neonates, we calculated the daily weight gain of neonates 7 days after birth. The survival rate of neonates was also calculated 14 days after birth. The result showed that arginine supplementation increased the daily weight gain of neonates (Table 2) and decreased the mortality caused by PCV2 infection (Fig. 2).

To understand the reason that arginine supplementation decreased the abortion rate, we measured the hormone levels which related with the pregnancy (progesterone and estrogen).Further, the NO level in serum was also detected to probe the arginine metabolism pathway in this special environment. SOD activity and T-AOC were also 
Table 1 Amino acid content in gestation measured by automatic amino acids analyzer

\begin{tabular}{ll}
\hline Amino acids content $(\mathrm{g} / 100 \mathrm{~g})$ & \\
\hline Aspartic acid & 1.66 \\
Threonine & 0.77 \\
Phenylalanine & 1.15 \\
Methionine & 0.24 \\
Serine & 1.00 \\
Glutamic acid & 3.74 \\
Glycine & 0.93 \\
Cystine & 0.9 \\
Valine & 0.71 \\
Proline & 2.49 \\
Leucine & 1.40 \\
Tyrosine & 1.28 \\
Lysine & 1.28 \\
Ammonia & 0.53 \\
Histidine & 0.36 \\
Arginine & 0.93 \\
Alanine & 0.91 \\
Isoleucine & 0.60 \\
\hline
\end{tabular}

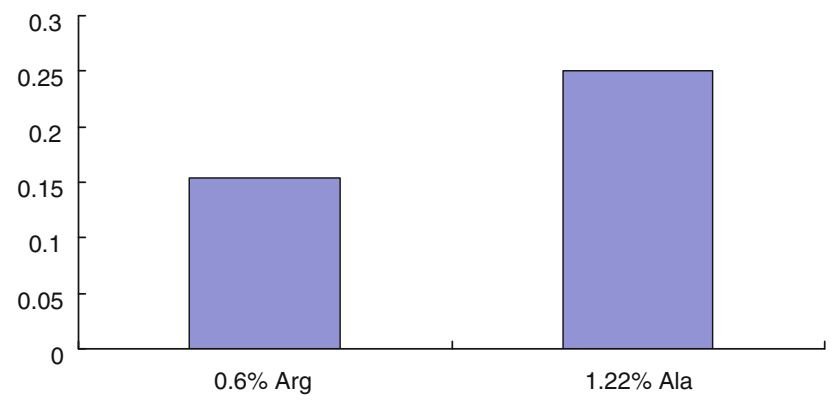

Fig. 1 The abortion rate in the arginine group and control group; $0.6 \%$ Arg means $0.6 \%$ arginine + gestation diet. $1.22 \%$ Ala means $1.22 \%$ alanine + gestation. Thirteen mice in the arginine group and 12 in the control group

measured to check the redox status in the body. Progesterone in the arginine group increased significantly $(P=0.006)$ (Table 3$)$ compared to the control, but arginine supplementation had little effect on the estrogen level $(P=0.167)$ (Table 3). Arginine supplementation had significant effect on the serum $\mathrm{NO}$ level as anticipated $(P=0.043)$ (Table 3). As in previous reports, SOD activity and T-AOC in the arginine groups were significantly higher than those of the control group (Table 4).

\section{Discussion}

The purpose of this paper was to test weather arginine supplementation inversed the reproductive failure of mice
Table 2 Effect of dietary arginine supplementation on the reproductive performance of mice infected with PCV2

\begin{tabular}{llrl}
\hline Catalog & $0.6 \%$ Arg & $1.22 \%$ Ala & $P$ value \\
\hline Litter number $^{\mathrm{a}}$ & $12.3 \pm 0.99$ & $11.89 \pm 0.96$ & 0.77 \\
$\begin{array}{l}\text { Litter birth weight } \\
\quad(\mathrm{g} / \text { mouse) }\end{array}$ & $1.78 \pm 0.05$ & $1.70 \pm 0.06$ & 0.30 \\
$\begin{array}{c}\text { Daily weight gain } \\
\text { (g/mouse day) }\end{array}$ & $0.37 \pm 0.04$ & $0.31 \pm 0.06$ & 0.06 \\
\hline
\end{tabular}

Data shown are least square means (LSM) \pm SEM

$0.6 \%$ Arg means $0.6 \%$ arginine + gestation diet; $1.22 \%$ Ala means $1.22 \%$ alanine + gestation

PCV2 porcine circovirus type 2

a 13 female mice in the arginine group and 12 female mice in the arginine group

b The mice were born by the mice infected with PCV2 after 7 days of pregnancy, respectively

${ }^{c} 60$ mice in the arginine group and 66 mice in the control group

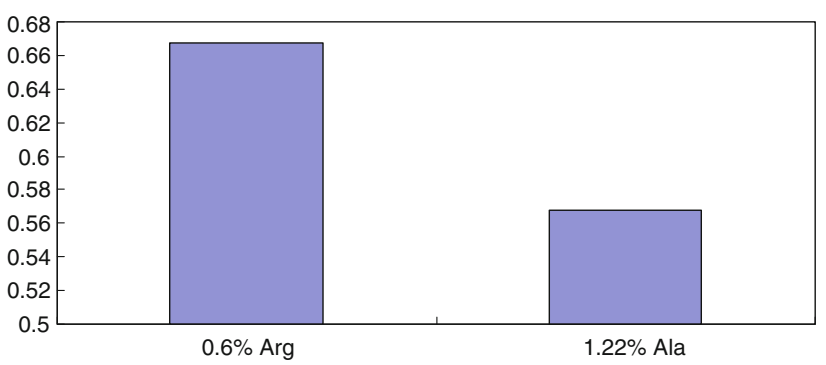

Fig. 2 The survival rate of neonates in the arginine group and the control group; $0.6 \%$ Arg means $0.6 \%$ arginine + gestation diet; $1.22 \%$ Ala means $1.22 \%$ alanine + gestation diet. Sixty mice in the arginine group and 66 mice in the control group. All the mice were born from female mice infected with PCV2 after 7 days of pregnancy. $P C V 2$ porcine circovirus type 2

Table 3 Effect of dietary arginine supplementation on the pregnancy-related hormones and serum $\mathrm{NO}$ level of mice infected with $\mathrm{PCV} 2$

\begin{tabular}{lllll}
\hline Catalog & $0.6 \%$ Arg & $1.22 \%$ Ala & $P$ value & $N$ \\
\hline $\begin{array}{c}\text { Progesterone } \\
(\mathrm{ng} / \mathrm{ml})\end{array}$ & $412.97 \pm 53.42 * *$ & $164.18 \pm 27.47 * *$ & 0.006 & 6 \\
$\begin{array}{c}\text { Estrogen } \\
(\mathrm{pg} / \mathrm{ml})\end{array}$ & $7,023.8 \pm 241.62$ & $7779.7 \pm 417.99$ & 0.169 & 6 \\
$\mathrm{NO}(\mu \mathrm{mol} / \mathrm{L})$ & $97.30 \pm 10.41^{*}$ & $23.6442 \pm 7.64 *$ & 0.043 & 6 \\
\hline
\end{tabular}

Data shown are least square means (LSM) \pm SEM

$0.6 \%$ Arg means $0.6 \%$ arginine + gestation diet; $1.22 \%$ Ala means $1.22 \%$ alanine + gestation

$N O$ nitric oxygen

$P C V 2$ porcine circovirus type 2

** $P<0.01, * P<0.05$

caused by PCV2 infection. The biggest problem when the PCV2 infected the sows was the abortion. We found that the abortion rate was nearly $28 \%$ and the survival rate of neonates was nearly $50 \%$ when we used the dose of 100 
Table 4 Effect of dietary arginine supplementation on the T-AOC and SOD of mice infected with PCV2

\begin{tabular}{lrlll}
\hline Catalog & \multicolumn{1}{l}{$0.6 \%$ Arg } & $1.22 \%$ Ala & $P$ value & $N$ \\
\hline T-AOC $(\mathrm{U} / \mathrm{ml})$ & $32.35 \pm 1.82^{* *}$ & $19.03 \pm 0.86^{* *}$ & 0.003 & 6 \\
SOD $(\mathrm{U} / \mathrm{ml})$ & $108.55 \pm 1.43^{* *}$ & $58.90 \pm 8.51^{* *}$ & 0.004 & 6 \\
\hline
\end{tabular}

Data shown are least square means $(\mathrm{LSM}) \pm$ SEM

$0.6 \%$ Arg means $0.6 \%$ arginine + gestation diet; $1.22 \%$ Ala means $1.22 \%$ alanine + gestation

$P C V 2$ porcine circovirus type 2

$S O D$ superoxide dismutase

$T$-AOC total antioxidant capacity

** $P<0.01$

TCID $_{50}$ PCV2 to infect the pregnant mice (data not shown). Arginine was generally considered as a nonessential amino acid, while, in situation of disease and infection, the production of endogenous arginine was likely impaired and it became a conditionally essential amino acid and could not meet demand. However, arginine displayed versatility in cell metabolism and physiology via itself or its metabolites (including NO and polyamines) (Wu and Bazer 2009): polyamines and NO were essential for placental growth and angiogenesis and for increasing uterine and placental-fetal blood flow. Greenberg et al reported that fetal resorption, intrauterine growth retardation, perinatal mortality and number of fetal death were increased when pregnant rats were fed arginine-free diets or on inhibiting NO synthesis (Greenberg and Lancaster 1997).

In this study, arginine supplementation decreased the abortion rate caused by PCV2 infection. In the control group, the abortion rate $(25 \%)$ which was less than in our previous result may be due to the advantages of alanine. However, the abortion rate decreased to $15.4 \%$ in the arginine group. To understand this result from the viewpoint of hormonal level, the serum progesterone and estrogen were measured. In agreement with the macroscopical result, progesterone in the arginine group was significantly higher $(P<0.01)$ than in the control group, but arginine supplementation had little effect on the serum estrogen level $(P>0.05)$. The high level of progesterone in the arginine group, a major hormone for establishment and maintenance of pregnancy, insured the decreased abortion rate (Bazer and Burghardt 2008). However, this result was in disagreement with $\mathrm{Li}$ et al. ( $\mathrm{Li}$ and Bazer 2010) who thought that dietary supplementation with $0.8 \%$ arginine beginning on day 0 of gestation reduced the circulating levels of progesterone in the maternal plasma. This may be because the different animal model and physiology environment changed the arginine metabolism pathway. The litter number and litter birth weight in the arginine group were a little higher than those of the control group. These results were similar to previous reports that dietary supplementation with arginine to gilts or rats increased the live-born litter weight by 24 and $30 \%$, respectively (Mateo and Wu 2007; Zeng and Wang 2008); the number of live-born piglets increased by two when fed the arginine-supplemented diet (Mateo and Wu 2007). However, in this study, the results of the litter number and litter birth weight were not significant as in previous studies, mainly because of the disadvantages of PCV2 infection. Further, the neonates' growth performance, including daily weight gain and survival rate, was better in the arginine group. The presumed main reason was that dietary arginine supplementation enhanced the immune response and clearance of PCV2. In addition, arginine supplementation had various advantages on the mammary gland (Lacasse and Farr 1996), including high arginine concentration, which was essential to insure their healthy growth (Kim and Wu 2004; Yao and Yin 2008).

T-AOC is an important integrative index used to reflect the total antioxidant capacity of the body. SOD is an important antioxidant enzyme that can decrease the destruction of the superoxide radical by catalyzing dismutation and $\mathrm{H}_{2} \mathrm{O}_{2}$ formation. So serum T-AOC and SOD activities are important indicators of the redox status. In this study, arginine supplementation increased T-AOC and SOD activities significantly $(P<0.01)$. This result was in agreement with the previous idea that arginine regulated cellular redox status and played a role in oxidative defenses (Fang and Yang 2002). One of the reasons was that arginine could synthesize glutamine, creatine and glutamate via arginase, which could upgrade glutathione synthesis in the animal cell (Wu and Morris 1998) and perform antioxidative function directly (Fang and Yang 2002). Oxidative stress has been indicated as a causative factor in pregnancyrelated disorders, such as embryonic resorption, recurrent pregnancy loss and fetal death (Gupta and Agarwal 2007). So, high T-AOC and SOD activity was partially responsible for the lower abortion in the arginine group.

There were multiple pathways for arginine degradation; the main pathways were initiated by arginase or three isoforms of nitric oxide synthase (Wu 2009). Research found that $2 \%$ of metabolized arginine was utilized for constitutive NO production in mammalian cells via nitric oxide synthase ( $\mathrm{Li}$ and Meininger 2001). NO played an important role in physiology, because it was the major endothelium-derived factor, a mediator of the immune response, a neurotransmitter, a cytotoxic free radical and a widespread signaling molecule (Ignarro and Cirino 1999).Furthermore, NO was an antimicrobial agent that was effective against intracellular pathogens, extracellular parasites and bacteria (Bermudez 1993; Pacelli and Wink 1995; Gobert and Daulouede 2000). In this study, the serum NO level in the arginine group was significantly higher $(P<0.05)$ than in the control group. This was in 
agreement with other studies, which indicated that arginine was the sole substrate for NO synthesis and dietary arginine deficiency in young rats decreased the plasma concentrations of arginine and impaired NO synthesis (Wu and Flynn 1999). This result also could explain the lower abortion, and the higher litter number and litter birth weight in the arginine group, because of advantages of higher NO.

All arginine supplementation inversed partially the reproductive failure in mice caused by PCV2 infection. The probable reasons may be the following. First, arginine or its metabolites as immunomodulator regulate the production of antibody by B cell, expression of the T-cell receptor and lymphocytes development (de Jonge and Kwikkers 2002).Large amount of evidences tested the immune function of arginine: whether arginine supplementation also increased peripheral lymphocyte mitogenesis in response to phytohemagglutinin and concanavalin $\mathrm{A}$ in humans (Barbul and Lazarou 1990). Dietary arginine supplementation enhanced immune response in various models of immunological challenges ( $\mathrm{Li}$ and Yin 2007). Second, arginine plays an important role in protein synthesis, urea cycle metabolism, synthesis of high-energy compounds and creatine phosphate. Arginine also stimulates the secretion of pancreatic hormones and anterior pituitary hormones, thereby regulating the metabolism of protein, amino acids, glucose and fatty acids. All these mechanisms help the host to adjust itself to an optimal status of defense against PCV2 infection.

However, the exact mechanism of arginine in PCV2 infection and the metabolism pathway involved in this special environment need further research. These results should be checked on pigs to measure the advantages of arginine supplementation.

Acknowledgments The authors thank A.W.Yuan, S.S.Cai, L.S.Yang and X.W.Tang for their technology support. The present work was supported by the National Key Technology R\&D Program in the 11th Five year Plan of China (No. 2008BADA7B00) and the National Basic Research Program of China (973 Program) (No. 2009CB118800).

Open Access This article is distributed under the terms of the Creative Commons Attribution Noncommercial License which permits any noncommercial use, distribution, and reproduction in any medium, provided the original author(s) and source are credited.

\section{References}

Barbul A, Lazarou SA, Efron DT, Wasserkrug HL, Efron G (1990) Arginine enhances wound healing and lymphocyte immune responses in humans. Surgery 108(2):331-336 (discussion 336-337)

Battegay EJ (1995) Angiogenesis: mechanistic insights, neovascular diseases, and therapeutic prospects. J Mol Med 73(7):333-346
Bazer FW, Burghardt RC, Johnson GA, Spencer TE, Wu G (2008) Interferons and progesterone for establishment and maintenance of pregnancy: interactions among novel cell signaling pathways. Reprod Biol 8(3):179-211

Bermudez LE (1993) Differential mechanisms of intracellular killing of Mycobacterium avium and Listeria monocytogenes by activated human and murine macrophages. The role of nitric oxide. Clin Exp Immunol 91(2):277-281

de Jonge WJ, Kwikkers KL, te Velde AA, van Deventer SJ, Nolte MA, Mebius RE et al (2002) Arginine deficiency affects early B cell maturation and lymphoid organ development in transgenic mice. J Clin Invest 110(10):1539-1548

Fan MZ, Li TJ, Yin YL, Fang RJ, Tang ZY, Hou ZP, Huang RL, Deng ZY, Zhong HY, Zhang RG, Zhang J, Wang B, Schulze H (2005) Effect of phytase supplementation with two levels of phosphorus diets on ileal and faecal digestibilities of nutrients and phosphorus, calcium, nitrogen and energy balances in growing pigs. Anim Sci 81:67-75

Fang YZ, Yang S, Wu G (2002) Free radicals, antioxidants, and nutrition. Nutrition 18(10):872-879

Flynn NE, Meininger CJ, Haynes TE, Wu G (2002) The metabolic basis of arginine nutrition and pharmacotherapy. Biomed Pharmacother 56(9):427-438

Gobert AP, Daulouede S, Lepoivre M, Boucher JL, Bouteille B, Buguet A et al (2000) L-Arginine availability modulates local nitric oxide production and parasite killing in experimental trypanosomiasis. Infect Immun 68(8):4653-4657

Greenberg SS, Lancaster JR, Xie J, Sarphie TG, Zhao X, Hua L, et al (1997) Effects of NO synthase inhibitors, arginine-deficient diet, and amiloride in pregnant rats. Am J Physiol 273(3 Pt 2): R1031-R1045

Gupta S, Agarwal A, Banerjee J, Alvarez JG (2007) The role of oxidative stress in spontaneous abortion and recurrent pregnancy loss: a systematic review. Obstet Gynecol Surv 62(5):335-347 (quiz 353-334)

Ignarro LJ, Cirino G, Casini A, Napoli C (1999) Nitric oxide as a signaling molecule in the vascular system: an overview. J Cardiovasc Pharmacol 34(6):879-886

Johnson CS, Joo HS, Direksin K, Yoon KJ, Choi YK (2002) Experimental in utero inoculation of late-term swine fetuses with porcine circovirus type 2. J Vet Diagn Invest 14(6):507-512

Kim J, Jung K, Chae C (2004) Prevalence of porcine circovirus type 2 in aborted fetuses and stillborn piglets. Vet Rec 155(16): 489-492

Kim SW, Wu G (2004) Dietary arginine supplementation enhances the growth of milk-fed young pigs. J Nutr 134(3):625-630

Kim SW, Mateo RD, Yin YL, Wu GY (2007) Functional amino acids and fatty acids for enhancing production performance of sows and piglets. Asian-Aust J Anim Sci 20:295-306

Lacasse P, Farr VC, Davis SR, Prosser CG (1996) Local secretion of nitric oxide and the control of mammary blood flow. J Dairy Sci 79(8):1369-1374

Ladekjaer-Mikkelsen AS, Nielsen J, Storgaard T, Botner A, Allan G, McNeilly F (2001) Transplacental infection with PCV-2 associated with reproductive failure in a gilt. Vet Rec 148(24): 759-760

Li X, Bazer FW, Johnson GA, Burghardt RC, Erikson DW, Frank JW et al (2010) Dietary supplementation with $0.8 \%$ L-arginine between days 0 and 25 of gestation reduces litter size in gilts. J Nutr 140(6):1111-1116

Li H, Meininger CJ, Hawker JR Jr, Haynes TE, Kepka-Lenhart D, Mistry SK et al (2001) Regulatory role of arginase I and II in nitric oxide, polyamine, and proline syntheses in endothelial cells. Am J Physiol Endocrinol Metab 280(1):E75-E82

Li P, Yin YL, Li D, Kim SW, Wu G (2007) Amino acids and immune function. Br J Nutr 98(2):237-252 
Mateo RD, Wu G, Bazer FW, Park JC, Shinzato I, Kim SW (2007) Dietary L-arginine supplementation enhances the reproductive performance of gilts. J Nutr 137(3):652-656

Mateusen B, Maes DG, Van Soom A, Lefebvre D, Nauwynck HJ (2007) Effect of a porcine circovirus type 2 infection on embryos during early pregnancy. Theriogenology 68(6):896-901

Mateusen B, Sanchez RE, Van Soom A, Meerts P, Maes DG, Nauwynck HJ (2004) Susceptibility of pig embryos to porcine circovirus type 2 infection. Theriogenology 61(1):91-101

Nieves C Jr, Langkamp-Henken B (2002) Arginine and immunity: a unique perspective. Biomed Pharmacother 56(10):471-482

O'Connor B, Gauvreau H, West K, Bogdan J, Ayroud M, Clark EG et al (2001) Multiple porcine circovirus 2-associated abortions and reproductive failure in a multisite swine production unit. Can Vet J 42(7):551-553

Pacelli R, Wink DA, Cook JA, Krishna MC, DeGraff W, Friedman N et al (1995) Nitric oxide potentiates hydrogen peroxide-induced killing of Escherichia coli. J Exp Med 182(5):1469-1479

Park JS, Kim J, Ha Y, Jung K, Choi C, Lim JK et al (2005) Birth abnormalities in pregnant sows infected intranasally with porcine circovirus 2. J Comp Pathol 132(2-3):139-144

Pensaert MB, Sanchez RE Jr, Ladekjaer-Mikkelsen AS, Allan GM, Nauwynck HJ (2004) Viremia and effect of fetal infection with porcine viruses with special reference to porcine circovirus 2 infection. Vet Microbiol 98(2):175-183

Rose N, Blanchard P, Cariolet R, Grasland B, Amenna N, Oger A et al (2007) Vaccination of porcine circovirus type 2 (PCV2)infected sows against porcine Parvovirus (PPV) and Erysipelas: effect on post-weaning multisystemic wasting syndrome (PMWS) and on PCV2 genome load in the offspring. J Comp Pathol 136(2-3):133-144

Segales J, Allan GM, Domingo M (2005) Porcine circovirus diseases. Anim Health Res Rev 6(2):119-142
Segales J, Rosell C, Domingo M (2004) Pathological findings associated with naturally acquired porcine circovirus type 2 associated disease. Vet Microbiol 98(2):137-149

Tan BE, Yin YL, Kong XF, Li P, Li XL, Gao HJ, Li XG, Huang RL, Wu GY (2010) L-Arginine stimulates proliferation and prevents endotoxin-induced death of intestinal cells. Amino Acids 38:1227-1235

Tan BE, Yin YL, Liu ZQ, Tang WJ, Xu HJ, Konga XF, Li XG, Yao K, Gu WT, Smith SB, Wu GY (2011) Dietary L-arginine supplementation differentially regulates expression of fat-metabolic genes in porcine adipose tissue and skeletal muscle. J Nutr Bioc 22:441-445

West KH, Bystrom JM, Wojnarowicz C, Shantz N, Jacobson M, Allan GM et al (1999) Myocarditis and abortion associated with intrauterine infection of sows with porcine circovirus 2. J Vet Diagn Invest 11(6):530-532

Wu G (2009) Amino acids: metabolism, functions, and nutrition. Amino Acids 37(1):1-17

Wu G, Bazer FW, Davis TA, Kim SW, Li P, Marc Rhoads J et al (2009) Arginine metabolism and nutrition in growth, health and disease. Amino Acids 37(1):153-168

Wu G, Flynn NE, Flynn SP, Jolly CA, Davis PK (1999) Dietary protein or arginine deficiency impairs constitutive and inducible nitric oxide synthesis by young rats. J Nutr 129(7):1347-1354

Wu G, Morris SM Jr (1998) Arginine metabolism: nitric oxide and beyond. Biochem J 336(Pt 1):1-17

Yao K, Yin YL, Chu W, Liu Z, Deng D, Li T et al (2008) Dietary arginine supplementation increases mTOR signaling activity in skeletal muscle of neonatal pigs. J Nutr 138(5):867-872

Zeng X, Wang F, Fan X, Yang W, Zhou B, Li P et al (2008) Dietary arginine supplementation during early pregnancy enhances embryonic survival in rats. J Nutr 138(8):1421-1425 